3. Auflage 1981 (überarbeitet 1990)

(c) Springer Fachmedien Wiesbaden 1990

Ursprünglich erschienen bei Betriebswirtschaftlicher Verlag Dr . Th. Gabler GmbH, Wiesbaden 1990.

Lektorat: Hans-Ulrich Bauer

Satz: SATZPUNKT Ewert, Braunschweig

Das Werk einschließlich aller seiner Teile ist urheberrechtlich geschützt. Jede Verwertung außerhalb der engen Grenzen des Urheberrechtsgesetzes ist ohne Zustimmung des Verlages unzulässig und strafbar. Das gilt insbesondere für Vervielfältigungen, Übersetzungen, Mikroverfilmung und die Einspeicherung und Verarbeitung in elektronischen Systemen.

ISBN 978-3-409-00735-1 ISBN 978-3-663-13502-9 (eBook)

DOI 10.1007/978-3-663-13502-9 


\section{Die Werbung in der Versicherungswirtschaft}

Von Dr. Ernst B e n n e r 
A. Grundlage der Werbung . . . . . . . . . . . . . . . . . . . 3

I. Allgemeine Grundsätze . . . . . . . . . . . . . . . . . . . . . . . . . 3

1. Werbung und Marktwirtschaft . . . . . . . . . . . . . . . . . . 3

2. Werbung, eine unternehmerische Aufgabe . . . . . . . . . . . . 4

II. Besonderheiten der Versicherungswirtschaft . . . . . . . . . . . . 5

1. Das unbegrenzte Angebot . . . . . . . . . . . . . . . . . . 5

2. Versicherung als Dienstleistung . . . . . . . . . . . . . 5

3. Tarife und Bedingungen ................ 5

B. Versicherungswerbung ...................... 6

I. Gemeinschaftswerbung .................... 6

1. Grundlagen .................... 6

2. Aufgaben und Themen ............... 6

II. Werbung des Einzelunternehmens . . . . . . . . . . . . . . . . . . 7

1. Werbung für das Unternehmen . . . . . . . . . . . . . . . . 7

2. Werbung für den Verbraucher ............... 8

C. Werbemittel und Werbeträger . . . . . . . . . . . . . . . . . . 9

I. Werbemittel ..................... 9

1. Mittel der Einzelwerbung . . . . . . . . . . . . . . 9 9

2. Mittel der Massenwerbung . . . . . . . . . . . . . . . 11

II. Werbeträger . . . . . . . . . . . . . . . . . . . . 15

1. Die Massenmedien ... . . . . . . . . . . . . . 15

2. Andere Werbeträger ................ 15

D. Planung . . . . . . . . . . . . . . . . . . . . . . 19

I. Das Werbeziel . . . . . . . . . . . . . . . . . . . . 20

II. Der Werbeetat . . . . . . . . . . . . . . . . . . . . . . . . . 20

1. Fixer Etat im Verhältnis zur Beitragseinnahme . . . . . . . . . . 21

2. Antizyklisch beeinflußter Etat . . . . . . . . . . . . . 21

3. Am Vorjahr orientierter Etat . . . . . . . . . . . . . . . 22

4. Etat für Sonderausgaben . . . . . . . . . . . . . . . 22

III. Die Werbeplanung . . . . . . . . . . . . . . . . . . . . . . 22

IV. Die Werbekontrolle . . . . . . . . . . . . . . . . . . . 23

1. Werbewirkung .................... 23

2. Werbeerfolg ................... 24 